\title{
Fanconi Anemia with Neuroblastoma Complicated by Acute Myelogenous Leukemia
}

\author{
Nura El-Haj ${ }^{1}$ and Carla Golden ${ }^{1}$ \\ ${ }^{1}$ UCSF Benioff Children's Hospital Oakland
}

September 11, 2020

\section{Fanconi Anemia with Neuroblastoma Complicated by}

\section{Acute Myelogenous Leukemia}

Running Title : Fanconi Anemia and Cancer Predisposition

Nura El-Haj, MD ${ }^{1}$; Carla B. Golden, $\mathrm{MD}^{1}$

${ }^{1}$ Department of Pediatric Hematology/ Oncology, University of California San Francisco, Benioff Children's Hospital, Oakland, California

Correspondence :

Nura El-Haj, MD

UCSF Benioff Children's Hospital Oakland

Department of Pediatric Hematology/ Oncology

$74752^{\text {nd }}$ St | Oakland, CA 94609

E-mail: nura.el-haj@ucsf.edu

tel. 510-428-3885 | fax. 510-601-3916

Word count: 494 words

Number of Figures : 1

Key words : Fanconi anemia; acute myelogenous leukemia; neuroblastoma; cancer predisposition

To the Editor:

Fanconi anemia (FA) is an inherited disorder characterized by mutations that impair DNA interstrand crosslinks repair and result in genomic instability, sensitivity to cytotoxic agents, and cancer predisposition. ${ }^{1}$ We present a case of FA with a VACTERL-like phenotype (anal, renal, cardiac, and limb defects) complicated by the development of two malignancies.

A one-day-old girl was referred for management of an imperforate anus and recto-vaginal fistula. She presented with microcephaly, microphthalmia, low set right ear, high-arched palate, choanal atresia, cutis aplasia, clinodactyly, and vertical talus. She had an atretic left kidney, ectopic right kidney, a patent foramen ovale, and a mid-muscular ventricular septal defect. A year later, surveillance abdominal ultrasonography detected a left upper quadrant mass. Computed tomography (CT) of the abdomen and pelvis defined a retroperitoneal mass and hepatic lesions with corresponding uptake on metaiodobenzylguanidine (MIBG) scan. Urine vanillylmandelic acid (VMA) was $209 \mathrm{ug} / \mathrm{mg}$ creat (normal <27), homovanillic acid (HVA) 116.1 
ug/mg creat (normal <33), neuron-specific enolase (NSE) $87.8 \mathrm{ng} / \mathrm{ml}$ (normal <10.8). Pathology confirmed poorly differentiated MYCN non-amplified neuroblastoma of unfavorable histology, with DNA index 1, and loss of heterozygosity at 1p and 11q23. Following one cycle of chemotherapy per COG ANBL0531 with etoposide and carboplatin, the patient developed hypoxemic respiratory distress, mucositis, liver dysfunction, gastrointestinal bleeding, and persistent fevers. Prolonged pancytopenia prompted a bone marrow evaluation: dysplastic megakaryocytes were seen but did not meet criteria for myelodysplastic syndrome [figure 1] . In addition to a known $1 \mathrm{p}$ cytogenetic abnormality, $5 \mathrm{q}$ deletion, gain of chromosome 17 , and additional material on 18q were detected. Subsequently, FA was diagnosed by Diepoxybutane (DEB) analysis on both blood and skin fibroblasts, and identification of a pathogenic mutation in PALB2. A month later, a bone marrow aspirate revealed acute myelogenous leukemia (AML) with $5 q$ and $7 q$ deletions. The patient passed away shortly thereafter from multiorgan dysfunction.

Less than $5 \%$ of infants with FA are diagnosed based on morphological features. ${ }^{2}$ In a series of 419 patients, one-third lacked obvious congenital abnormalities. ${ }^{3}$ Moreover, 18 of $54(33 \%)$ patients with FA from the NIH Inherited Bone Marrow Failure Registry met criteria for VACTERL with hydrocephalus (VACTERL-H).

Furthermore, children harboring FANCD1/BRCA2 and FANCN/PALB2 mutations have an increased likelihood of developing a solid malignancy. ${ }^{1}$ This child's PALB2 gene mutation encoding a BRCA2-interacting protein $^{5}$ may have contributed to the development of neuroblastoma. Children with these mutations have a cumulative incidence of leukemia of $80 \%$ by age 10 and chromosomal gains 1q, 3q, 13q, and monosomy 7 confer an increased risk. ${ }^{6-8}$ We illustrate that patients with FA have a genetic cancer predisposition and their risk is likely also greater after exposure to chemotherapy.

Lastly, allogeneic hematopoietic stem cell transplantation was discussed. Strategies to reduce conditioning regimen toxicity and graft-versus-host disease related morbidity have been developed. ${ }^{9-12}$ However, comfort care was favored given clinical deterioration.

This case highlights diagnostic and therapeutic challenges presented by this phenotypically heterogeneous disease and call for FA screening in patients suspect to have VACTERL to enable early diagnosis of the disease.

\section{References}

1. Malric A, Defachelles AS, Leblanc T, et al. Fanconi anemia and solid malignancies in childhood: a national retrospective study.Pediatric blood \& cancer. 2015;62(3):463-470.

2. Auerbach AD. Fanconi anemia and its diagnosis. Mutation research. 2009;668(1-2):4-10.

3. Giampietro PF, Adler-Brecher B, Verlander PC, Pavlakis SG, Davis JG, Auerbach AD. The need for more accurate and timely diagnosis in Fanconi anemia: a report from the International Fanconi Anemia Registry. Pediatrics. 1993;91(6):1116-1120.

4. Alter BP, Giri N. Thinking of VACTERL-H? Rule out Fanconi Anemia according to PHENOS. American journal of medical genetics. Part A. 2016;170(6):1520-1524.

5. Tischkowitz M, Xia B. PALB2/FANCN: recombining cancer and Fanconi anemia. Cancer research. 2010;70(19):7353-7359.

6. Alter BP. Fanconi anemia and the development of leukemia. Best practice \& research. Clinical haematology. 2014;27(3-4):214-221.

7. Mehta PA, Harris RE, Davies SM, et al. Numerical chromosomal changes and risk of development of myelodysplastic syndrome-acute myeloid leukemia in patients with Fanconi anemia. Cancer genetics and cytogenetics. 2010;203(2):180-186.

8. Quentin S, Cuccuini W, Ceccaldi R, et al. Myelodysplasia and leukemia of Fanconi anemia are associated with a specific pattern of genomic abnormalities that includes cryptic RUNX1/AML1 lesions. Blood.2011;117(15):e161-170.

9. MacMillan ML, DeFor TE, Young JA, et al. Alternative donor hematopoietic cell transplantation for Fanconi anemia. Blood.2015;125(24):3798-3804.

10. Yabe H, Inoue H, Matsumoto M, et al. Allogeneic haematopoietic cell transplantation from alterna- 
tive donors with a conditioning regimen of low-dose irradiation, fludarabine and cyclophosphamide in Fanconi anaemia. British journal of haematology. 2006;134(2):208-212.

11. Flowers ME, Zanis J, Pasquini R, et al. Marrow transplantation for Fanconi anaemia: conditioning with reduced doses of cyclophosphamide without radiation. British journal of haematology.1996;92(3):699706.

12. Wagner JE, Eapen M, MacMillan ML, et al. Unrelated donor bone marrow transplantation for the treatment of Fanconi anemia. Blood.2007;109(5):2256-2262
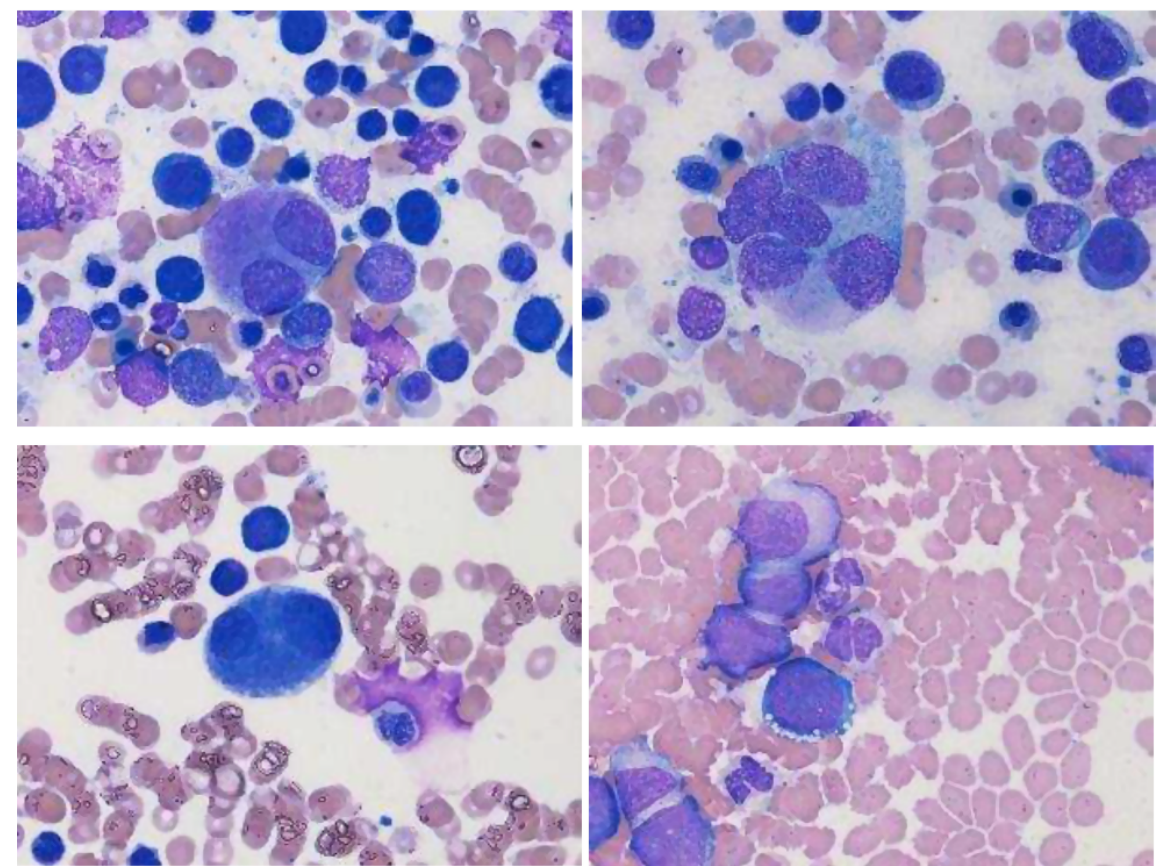